\title{
Technology Foresight on China's Engineering Science and Technology to 2035
}

\author{
Wang Kunsheng ${ }^{1}$, Zhou Xiaoji ${ }^{1}$, Gong $\mathrm{Xu}^{2}$, Hu Liangyuan ${ }^{1}$, Sun Shengkai ${ }^{1}$, Song Chao ${ }^{1}$, Hou Chaofan ${ }^{1}$, \\ Chen Jindong ${ }^{1}$
}

1. China Aerospace Academy of Systems Science and Engineering, Beijing 100048, China

2. National Natural Science Foundation of China, Beijing 100085, China

\begin{abstract}
Technology foresight is a process that promotes the integration of technology, the economy, and major planning projects, and explores the development of future technologies. In consideration of the future economic and social development needs of our country, technology foresight in development strategy research on engineering science and technology involves predicting and selecting key technologies for the next 20 years. By combining objective analysis with subjective judgment, the methods and procedures applied in the technology foresight on China's engineering science and technology to 2035 were designed by considering the characteristics of engineering science and technology. This technology foresight selects key, common, and disruptive technologies from more than 800 technologies in 11 fields, and analyzes their technical realization time, development level, and constraints. The results of this technology foresight are adopted to create a technology roadmap for China's engineering science and technology development for 2035 , in various fields.
\end{abstract}

Keywords: technology foresight; engineering science and technology; 2035; key technology selection; realization time

\section{Introduction}

Technology foresight is a step-by-step, systematic process that explores future technological developments and their social impacts, puts technological change prediction and planning into a socio-economic context in a bid to promote the integration of technological progress and economic development, and optimizes scientific, technological, economic, environmental, and social resources. Technology foresight, as a growing international trend in science and technology policy research and policymaking, provides a new mechanism for promoting future science and technology achievements in line with a holistic approach to economic, social, and technological development.

The technology foresight programs of Japan and the UK are representative national technology foresight programs. Tech- nology foresight has been conducted in Japan every five years since 1970. So far, Japan, as the most influential country in this area, has implemented ten technology foresight surveys. Mainly based on the Delphi survey in its early stage, the main purpose of Japan's technology foresight program is to contribute to science and technology policymaking. Since then, methods such as needs survey, citation analysis, scenario analysis, and vision investigation have been adopted, in a bid to address major global and national challenges, and facilitate national and regional innovation-related policymaking. In 2015, Japan conducted its tenth technology foresight survey, known as "problem-solving scenario planning," which centered on the integration of science and technology policies and innovation policies, to set up a future scenario based on social vision investigation and science and technology development evaluation [1]. The technology

Received date: 25 December 2016; revised date: 10 January 2017

Corresponding author: Wang Kunsheng, China Aerospace Academy of Systems Science and Engineering, Researcher. Major research fields include system engineering and computer technology. E-mail: wangks@spacechina.com

Funding program: CAE Advisory Project "Research on China's Engineering Science and Technology Development Strategy 2035" (2015-ZD-14); National Natural Science Foundation Project of China (NSFC-L1524024)

Chinese version: Strategic Study of CAE 2017, 19 (1): 034-042

Cited item: Wang Kunsheng et al. Technology Foresight on China's Engineering Science and Technology to 2035. Strategic Study of CAE, https://doi.org/10.15302/ J-SSCAE-2017.01.006 
foresight program of the UK was launched in the 1990s. In 2002, the UK shifted to a flexible, rolling mechanism for project selection, with each project centered on a key issue such as "cognitive systems," "global environmental migration," "technology and innovation futures," "future recognition technologies," "future manufacturing," etc. Current projects include "future of an ageing population" and "future of cities" [2,3]. Over the past decade, South Korea, Brazil, Russia, and other emerging economies emphasized the importance of technology foresight exercises as a tool for planning long-term industrial strategies and policies, and for promoting economic, social, and technological development.

Technology foresight exercises emerged in China at the beginning of the 21 st century, led by the Ministry of Science and Technology and the Chinese Academy of Sciences. The Ministry of Science and Technology has conducted the technology foresight survey every five years since 2002, to support the formulation of China's national science and technology plan. In 2015, the technology foresight survey and the review of key technologies covered by the science and technology planning for the 13th Five-Year Plan were completed. In 2003, the Chinese Academy of Sciences launched a national technology foresight program, focusing on the technological developments in the next 20 years, and completed technology foresight research works in four different fields in 2005 and 2008 [4]. Shanghai and Beijing launched their technology foresight initiatives in 2001. In particular, Shanghai has since conducted three rounds of research. The first round of research introduced methods such as technology roadmap and patent map. Vision and needs investigation were covered in the second round. Starting in 2013, the third round included mid- and long-term technology foresight research, and was part of the groundwork for formulating Shanghai's science and technology planning for the 13th Five-Year Plan [5]. Meanwhile, Guangdong, Wuhan, Tianjin, Yunnan, Shandong, and Xinjiang have also launched their technology foresight studies.

Since the second half of the 20th century, technology foresight has become an important method for the research and development of global science and technology policies. Many countries and regions have been engaged in promoting technology foresight in different sectors. Technology foresight presents a new dimension in the 21 st century, i.e., it is not just about predicting the future, but about shaping the future by guiding the way for social engagement. The direction of surveys and the analysis of the results attach more importance to the needs and challenges of the future, with the focus shifting to the uncertainty and revolution of technology as well as to the formation of technology clusters for industrial development.

The "Technology Foresight on China's Engineering Science and Technology to 2035" is part of the "Research on China's Engineering Science and Technology Development Strategy 2035," a technology foresight program jointly championed by the Chinese Academy of Engineering and the National Natural Science
Foundation of China. The purpose of this strategic research program is to identify the objectives, key areas, and key technologies to be created, along with major projects to be conducted and basic research directions to be undertaken with priority over the period up to 2035, and to provide consultation services to the country's systematic planning and prospective deployment for basic research in the engineering sector and related areas. To ensure a forward-thinking and scientific approach to strategic research for engineering science and technology, the technology foresight program explores the science and technology trends, both domestically and abroad, and suggests the most likely science and technology developments in engineering over the next two decades. Based on the country's strategic, economic, and social development needs, science and technology directions and technological breakthroughs, together with the timeframe for realization, level of sophistication, and constraints, are examined from a holistic and long-term perspective to form a foundation for the strategic research on China's engineering science and technology for 2035 .

\section{Technology foresight on China's engineering science and technology to 2035: methods and procedures}

The technology foresight survey, as an integral part of the "Research on China's Engineering Science and Technology Development Strategy 2035," focuses specifically on science and technology topics in engineering. Therefore, it is important to design and apply research methods suitable for studying science and technology development strategies in engineering. The methods and processes designed and adopted for the survey are as follows.

\subsection{Research methods}

Four factors are considered in selecting the research methods for the technology foresight on China's engineering science and technology to 2035 :

(1) Based on the purpose of technology foresight, engineering science and technology fields are categorized, lists of science and technology topics are reviewed, and questions are formulated according to the scope of the development strategy research, with emphasis on technological feasibility and usability.

(2) Needs analysis is used for technology foresight, highlighting the role of engineering in economic and social development, and evaluating the impact of needs as a driving force. A combination of future vision and needs analysis provides an important basis for preparing the list of engineering science and technology topics.

(3) Qualitative methods such as expert workshops and the Delphi survey are combined with quantitative methods such as bibliometrics and patent analysis. On the one hand, inputs from 
academicians and experts from the Chinese Academy of Engineering and the National Natural Science Foundation are collected. On the other hand, the list of candidate science and technology topics is prepared, reviewed, and revised through statistical analysis of publications and patent information. In this process, the findings of foresight studies are validated.

(4) The integration of technology foresight and strategic research is enhanced. Based on the requirements of practical research, the interval time between two Delphi surveys is prolonged. Topic-specific studies shall be conducted on the basis of the findings of the first-round Delphi survey and needs analysis, with the controversial issues or key technologies identified in the first round of research being carefully examined. As the stra- tegic research proceeds, the second round of research shall be launched with a better understanding of the technology trends, allowing the questions of the second survey to be more targeted and more relevant to the strategic research.

The methods and procedures for the technology foresight on China's engineering science and technology to 2035 are shown in Fig. 1.

\subsection{Formation of technology foresight fields and candidate topics}

The technology lists for the technology foresight on China's engineering science and technology to 2035 are formulated at

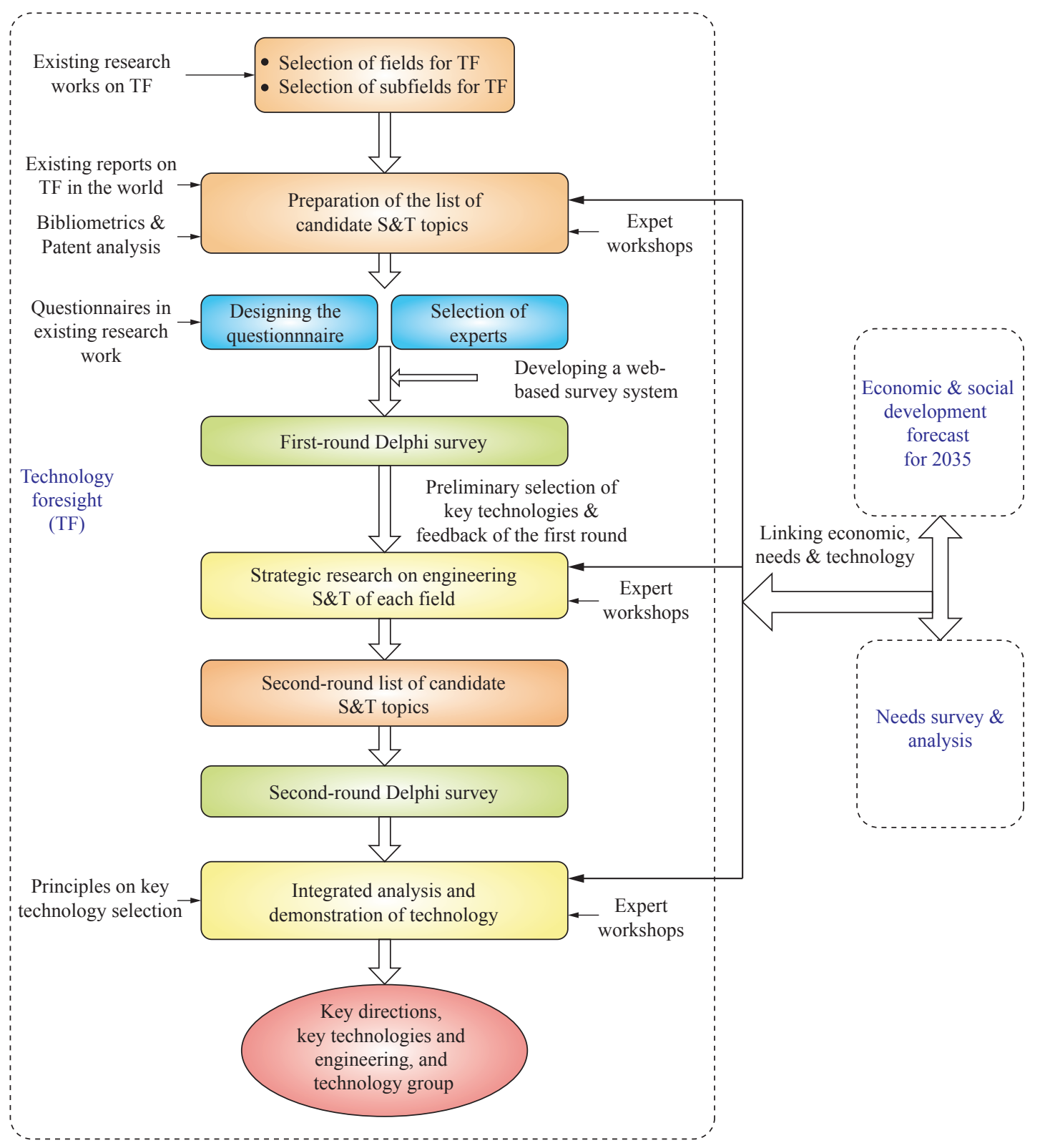

Fig. 1. Thought and procedure design for the technology foresight on China's engineering science and technology to 2035. 
three levels, i.e., fields, subfields, and items. The selection principles and list formation are as follows.

\subsubsection{Categorization of covered fields}

The categorization of fields covered by the technology foresight survey depends on the underlying purpose of the survey and the way it is implemented. Through the study of the methodologies for selecting technology fields in technology foresight exercises, both domestically and abroad, and considering the characteristics and needs of strategic research on engineering science and technology, two principles for categorization have been defined. First, from the perspective of the discipline of engineering, the main areas and key directions of engineering science and technology should be covered, highlighting the impact on economic and social development. Second, from the perspective of technology foresight, the hot topics and cross-domain or multidisciplinary topics should be covered. After several rounds of discussion, 11 fields were selected, i.e., information and electronics; advanced manufacturing; advanced materials; energy and mining; environment and green manufacturing; space, ocean, and earth; urbanization and infrastructure; transportation; agriculture and food; medical care and health; and public security. Ninety-eight subfields were identified, accordingly.

2.1.2 Preparation of the list of candidate science and technology topics

This technology foresight survey is targeted at the specific fields covered by the strategic research on engineering science and technology, and is scheduled to be completed during the early phases of the strategic research. Meanwhile, given the extremely broad scope of the discipline of engineering, seeking opinions extensively on the list of technology topics is impractical within such a short period of time. Therefore, the preliminary list of engineering science and technology topics was prepared from the recent technology foresight exercises at home and abroad, especially the Ministry of Science and Technology's latest technology foresight list. The basic principles for list formation include: (1) Science and technology topics should meet the strategic needs of China's economic and social development, and take into account the global mega-trends; (2) science and technology topics are expected to achieve a major breakthrough and become popular in the next one or two decades and generally enjoy a certain level of competitiveness; and (3) science and technology topics should include disruptive innovations or high-potential technological developments.

The preparation of the list of candidate technologies included mainly five steps: (1) Panel discussions were held for each field/ item of strategic research, and a preliminary list of science and technology topics was created; (2) future directions of technological development were identified and validated through bibliometrics, patent analysis, etc., particularly in "robotics" and "3D printing"; (3) expert workshops were held or written requests were sent to seek inputs on candidate topics, e.g., opinions from academicians were collected during the CAE Conference 2015 and the first-round list of candidate science and technology topics was formulated after being reviewed, rated, assessed, and revised; (4) new science and technology topics were discovered during the first round of the Delphi survey; and (5) the list of science and technology topics was further revised on the basis of the results of the first round of expert survey and field-specific strategic research; meanwhile, more experts were invited to propose new science and technology topics. In this way, the second-round list of candidate science and technology topics was finalized.

\subsection{Expert survey}

An expert survey is an essential part of technology foresight, involving two or more rounds of questionnaire surveys of a wide range of experts, to fully understand the predictions and expectations of the community about the future vision of technological development.

\subsubsection{Questionnaire and survey system design}

A questionnaire was designed to collect expert inputs on the five aspects of the candidate science and technology topics, i.e. importance of the technology itself, importance of the application of the technology, predicted realization time, technology infrastructure and competitiveness, and constraints. In particular, questions about the aspect of the importance of the technology itself examined the characteristics of a science and technology topic such as the technology core, commonality, driving ability, and discontinuity; questions about the importance of application of the technology explored the impact on the economy, society, and national security/national defense. The aspect of predicted realization time was further broken down into technology realization time (worldwide), technology realization time (in China), and social realization time (in China). For a comprehensive understanding of how experts would feel about technological developments in the future, a few open-ended questions were included in the questionnaire, such as the important directions of science and technology development outside the list of candidate science and technology topics, new products in 2035, the likely directions of fundamental research, etc.

A web-based survey system was developed for this technology foresight survey. The online questionnaire was designed such that it was simple to answer the questions, provide easy access to information, and ensure that the responses were relevant to the questions asked. Respondents were able to complete the questionnaire online in an intuitive and flexible manner, allowing the survey to be conducted and feedback to be collected between rounds efficiently. In addition, the online survey system provided an admin page, so that the field-specific technology foresight ad- 
ministrator could gain access to real-time data, monitor progress, and take action accordingly.

\subsubsection{Expert selection}

The technology foresight survey covers a range of specialized fields of engineering, and requires a wide spectrum of leading experts from R\&D institutions, academia, the government, and the industry, in order to ensure that the results of the survey reflect opinions on $\mathrm{R} \& \mathrm{D}$, technological application, economic and social needs, industrial development, etc. The expert network originally had nearly 8000 experts, mainly through invitation or recommendation. During the technology foresight survey, approximately 2000 experts joined the network through online recommendation.

Simultaneously, in line with the requirements of the strategic research project, a survey of economic and social needs for 2035 is conducted, which helps make the needs analysis more relevant to the technology foresight and strategic research projects.

\section{Results of the technology foresight survey}

The technology foresight project was launched in March 2015. After the list of candidate science and technology topics was selected, two rounds of expert survey were conductedthe first round from August 2015 to October 2015 and the second round from May 2016 to July 2016 - to provide the preliminary results of China's engineering science and technology predictions for 2035. Subsequently, academicians and experts from various engineering fields discussed and reviewed the outputs of these surveys, in a bid to identify the key technological directions and develop the field-specific technology roadmaps.

\subsection{Responses to the expert survey}

The second round of expert survey received 29542 responses, i.e., 36.2 responses for each science and technology topic. About $32 \%$ of the respondents were from research institutions, $44 \%$ from academia, and the rest from business and the government,

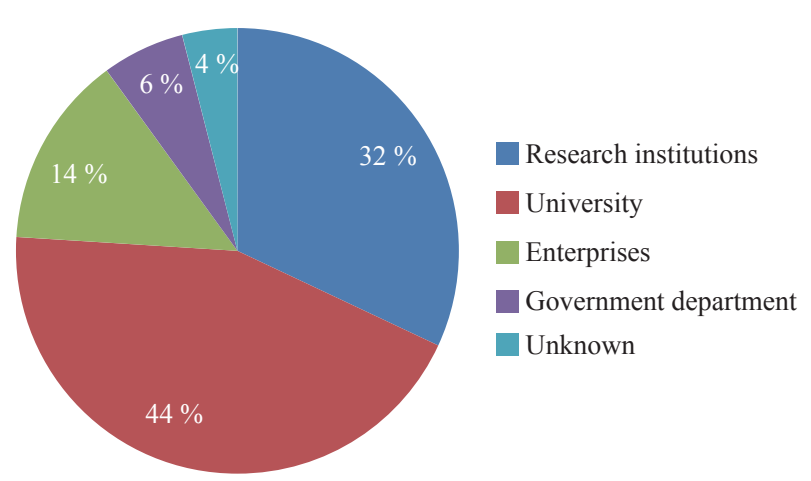

Fig. 2. Distribution of the participating experts' affiliated organizations. as shown in Fig. 2, which suggests that i) Chinese universities and research institutions have attracted a large number of technical experts and that ii) it is necessary to raise awareness about the engagement of technology foresight in the business world. Fifty-six percent of the respondents said that they were "very familiar" or "familiar" with the science and technology topics selected, and only $1 \%$ of the respondents were "unfamiliar" ("unfamiliar" responses were not considered in the statistical analysis), suggesting a high level of professional expertise, as shown in Fig. 3.

\subsection{Analysis of technology infrastructure and competitiveness}

In the questionnaire survey, the experts were asked to describe "the current level of R\&D of the technology project in China," i.e., "internationally leading," "close to the international level," or "behind the international level." The distribution of the scores for the level of R\&D in various fields is shown in Fig. 4, specifically, 20 points and below for "behind the international level," 40-60 points for "close to the international level," and 80 points and above for "internationally leading." China, as a whole, is behind the international level in terms of the level of $R \& D$, whereas the overall level of its $R \& D$ in the field of advanced materials is relatively higher.

In the questionnaire survey, experts were also asked to describe "the current leading country in the technology" to evaluate the technological competitiveness of major economies. The distribution of the results for the leading country in various fields is shown in Fig. 5. The United States, overall, is internationally leading, whereas the EU is leading in the field of environmental ecology and green manufacturing.

China has some advantages in energy and mining, transportation, and medical care and health. A further analysis of the subfields and technology project indicated that China enjoys strong technological advantages in Chinese medicine, high-speed rail construction, coal mining, power generation, hydroelectric power generation, etc. However, China lags far behind in equipment manufacturing, deep-sea resources exploration and utilization, green production, urban management, etc.

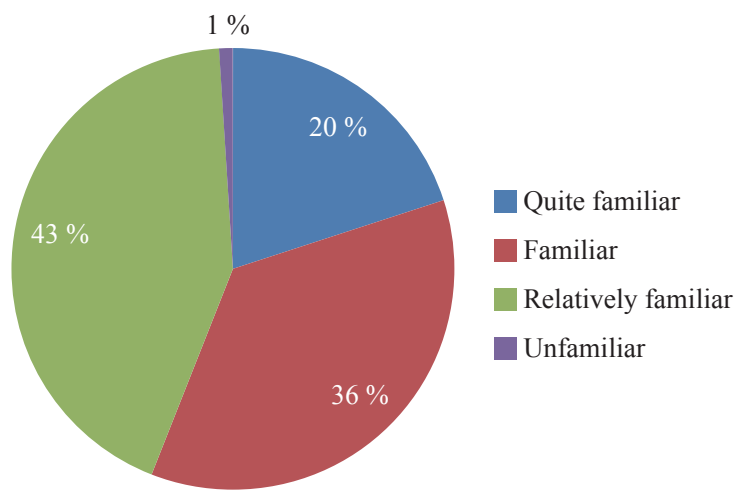

Fig. 3. Distribution of the experts' familiarity with the technologies. 


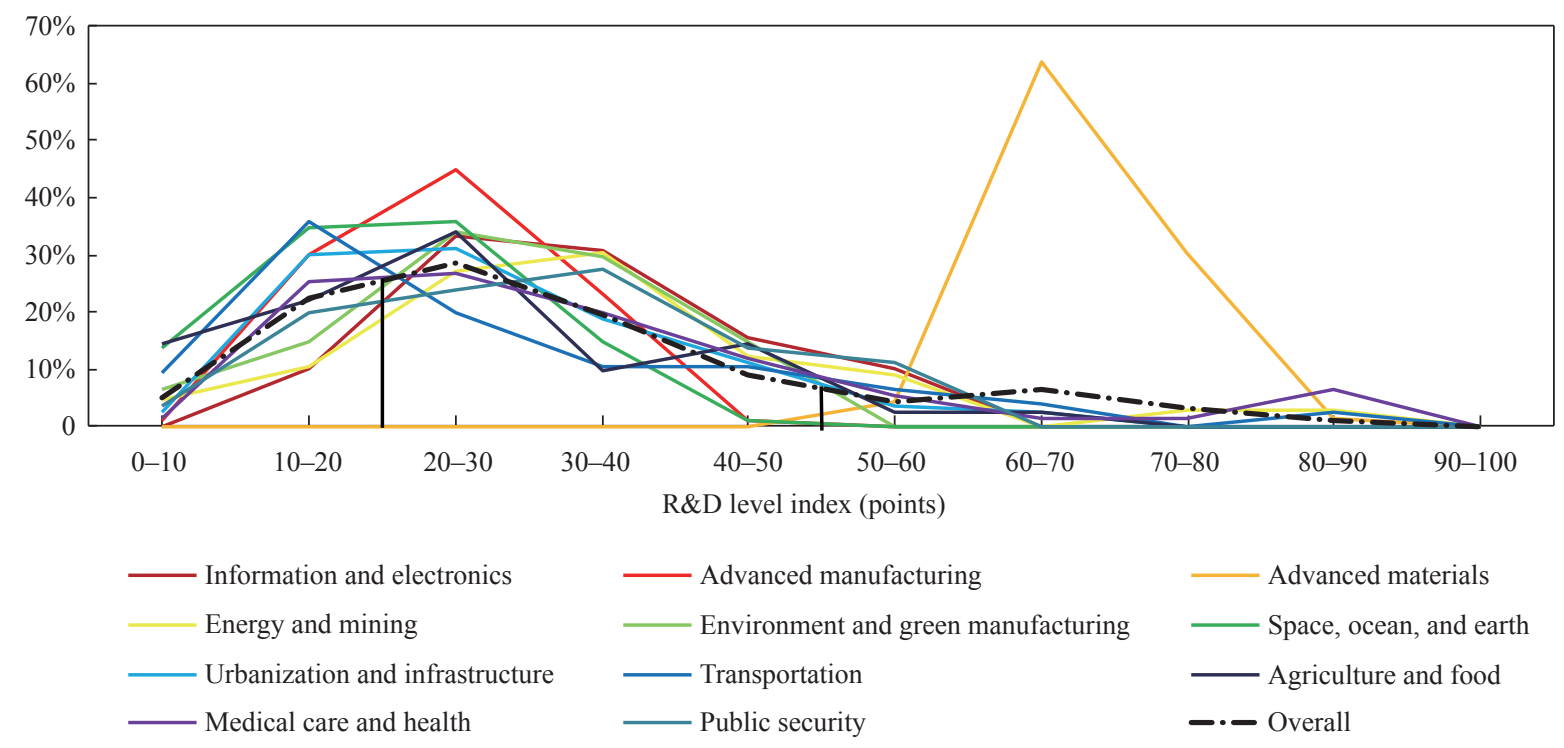

Fig. 4. Distribution of the level of technological R\&D by each field.

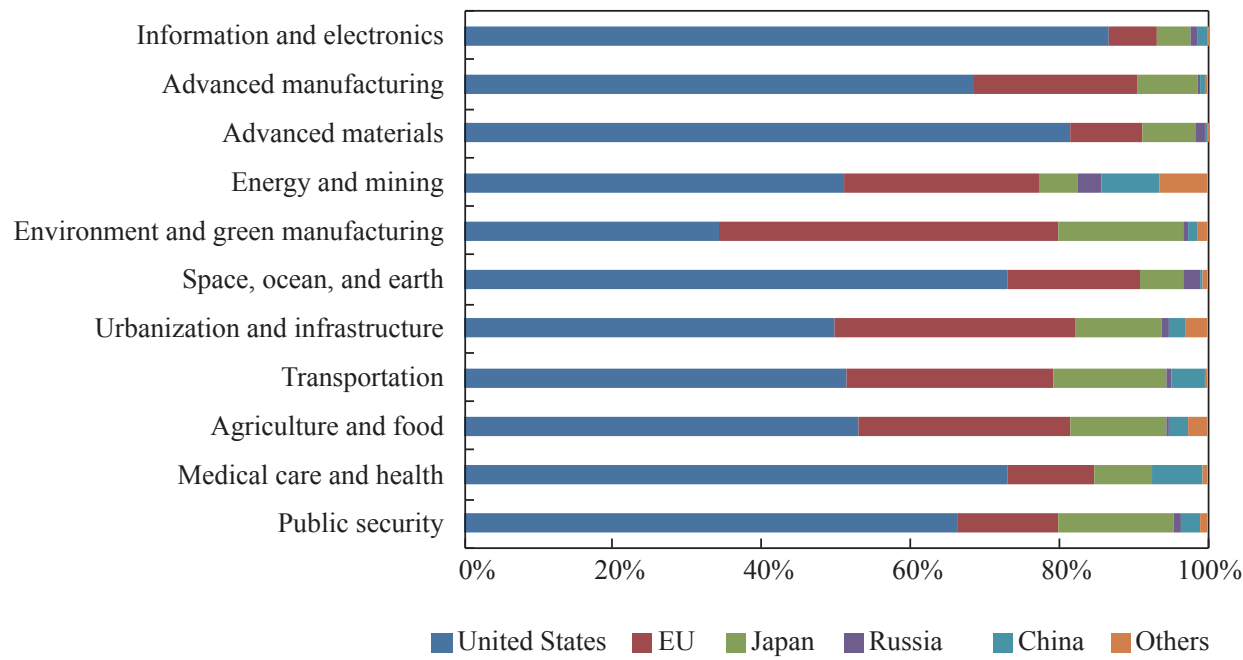

Fig. 5. Distribution of leading countries in technology by each field.

\subsection{Technological realization and application time prediction}

The results for the "predicted time of technological realization" are shown in Fig. 6. The technological realization time being reviewed tends to follow a normal distribution. In particular, the predicted time of technological realization is between 2024 and 2027 in China, i.e., 4-6 years behind that of the international leader; the predicted time of social realization of technology is between 2026 and 2030 in China, i.e., 3-5 years behind that of technological realization, suggesting a time lag between technological R\&D and real-world implementation.

In the questionnaire survey, experts were asked about the "constraints of development of the technology." The distribution of constraints in various fields is shown in Fig. 7. Overall, talent, science and technology resources, and R\&D investment are key constraints in the development of all fields. In particular, talent, science, and technology resources are two obvious constraints restricting the technological progress in the field of materials, accounting for more than $50 \%$. Laws, regulations, and policies, and standards and specifications are the more constraining factors in the field of environmental ecology. The capability of industrial bases is the main factor hampering advanced manufacturing, energy, and transportation.

\subsection{Key technology selection}

On the basis of the project design and expert survey and assessment, this technology foresight project gives a full picture of the key technologies, common technologies, and disruptive technologies in China's engineering sector up to 2035, combined 


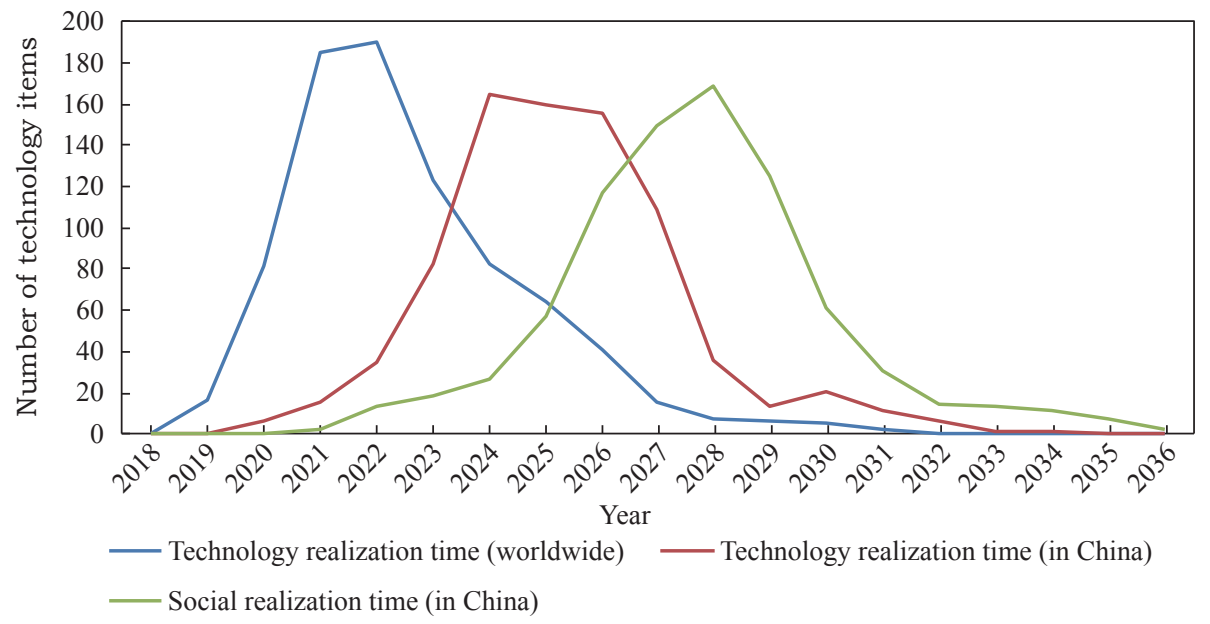

Fig. 6. Predicted time of technological realization.

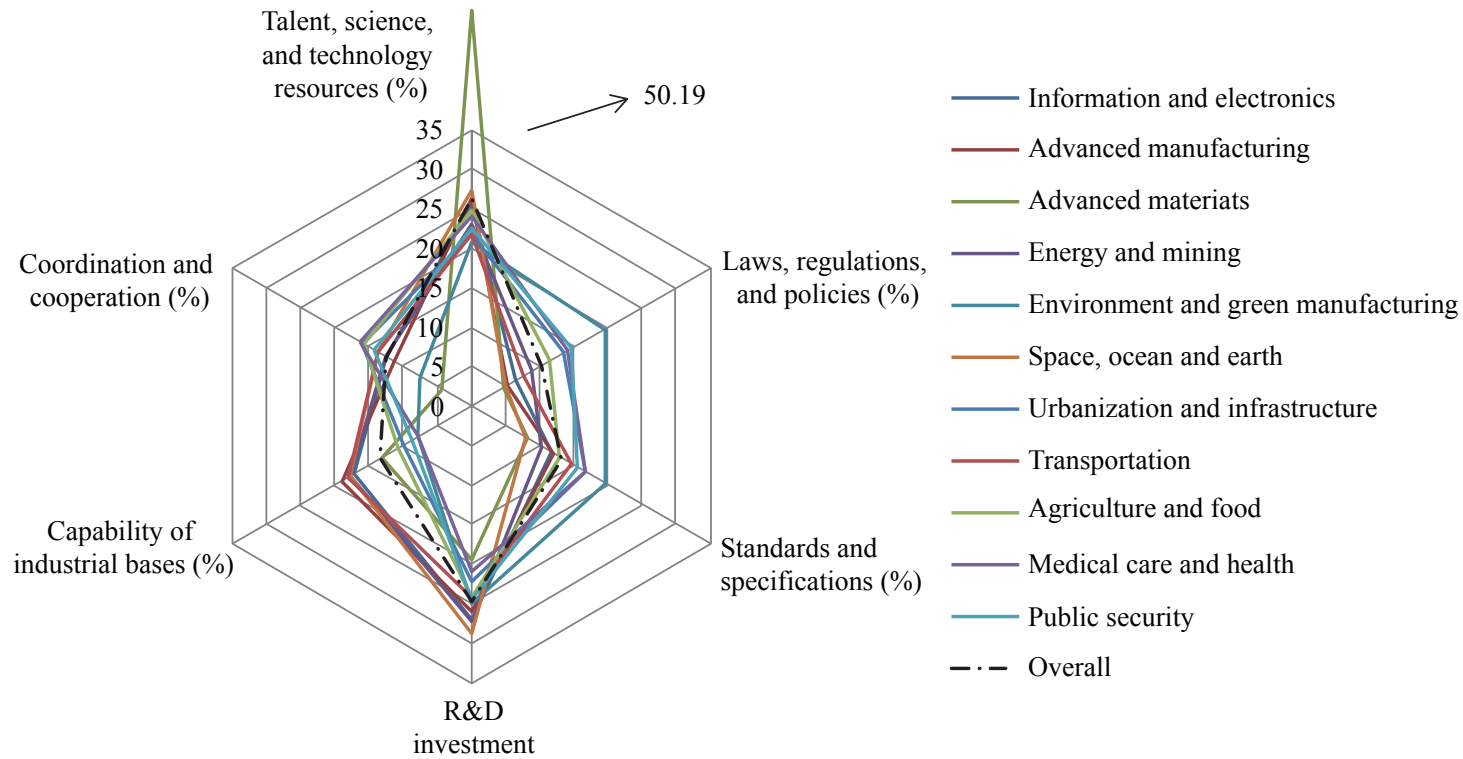

Fig. 7. Distribution of the constraints of technological development.

with the research of experts. In particular, the results of the survey will be used to evaluate technology in terms of importance and the importance of application, in order to determine the candidate key technological directions. The candidate common technologies are identified by taking into account their universality and the importance of the application scores; candidate disruptive technologies are recognized by considering the discontinuity and the importance of the application scores. After that, expert reviews are held to assess more than 800 candidate technologies and finalize the lists of 100 key technologies, 50 common technologies, and 20 disruptive technologies. Table 1 shows 25 important technological directions with certain representativeness for 2035 .

Big data, robotics, sensor, and remote sensing account for a large part of common technologies, fully embodying the wide application prospect of the future information technology in each industry and field. In disruptive technologies, there are many technologies, such as new types of materials, unmanned technology, and zero emission, reflecting significant challenges and problems of the future technology development in the fields of labor liberation, productivity enhancement, environmental friendship, etc.

\section{Conclusions}

As the first technology foresight activity implemented under the long-term strategic research on engineering science and technology, the technology foresight on China's engineering science and technology to 2035 is conducted to support requirement-based strategic research. The methods and procedures for technology foresight are designed after a series of preliminary research, taking into account the characteristics of engineer- 
Table 1. Important technological directions with certain representativeness for 2035.

\begin{tabular}{|c|c|}
\hline No. & Technology items \\
\hline 1 & Advanced computing technology \\
\hline 2 & Integrated information network of sky, space, land, and sea, and new type of communication technology \\
\hline 3 & Key technologies of artificial intelligence and brain simulation \\
\hline 4 & Intelligent $\mathrm{CNC}$ machining unit/system \\
\hline 5 & Man-machine interactive robotics technology \\
\hline 6 & Micro-nano 3D printing technology \\
\hline 7 & New concept of aerodynamics technology \\
\hline 8 & High-power laser and nonlinear optical crystal, device, and application technology \\
\hline 9 & High-performance fiber materials \\
\hline 10 & Comprehensive smart grid-based energy system technology \\
\hline 11 & Intelligent mining technology \\
\hline 12 & Source energy conservation, emission reduction, and high-efficient metallurgical reactor technology \\
\hline 13 & Prevention and safe utilization technology of microbial-contaminated water of groundwater and drinking water \\
\hline 14 & Key technologies of urban center upgrading and redevelopment \\
\hline 15 & Key technologies of urban safety operation and toughness enhancements \\
\hline 16 & Key technologies of a new type of high-performance architecture \\
\hline 17 & Multidimensional perception and real-time coprocessing of traffic-related big data technology \\
\hline 18 & Multi-hazard risk assessment and accident prevention for chemical facilities technology \\
\hline 19 & Scalable-applied desalination technology and equipment \\
\hline 20 & Numerical ocean modeling science and technology \\
\hline 21 & Deep-sea exploration and operation technology \\
\hline 22 & Key technologies of intelligent agricultural machinery \\
\hline 23 & Gene mining and big data genomics-based technology for crop and livestock breeding \\
\hline 24 & New technology and application of cell/tissue repair and organ regeneration \\
\hline 25 & Key technologies of new drug discovery and pharmaceutical engineering \\
\hline
\end{tabular}

ing technology and the requirements of strategic research, and maintaining a focus on overall coordination and process management, to ensure that the technology foresight is effectively implemented and successfully completed. A systematic, disciplined approach to technology foresight is developed for the strategic research on engineering science and technology, providing strong support for the research activities in various fields covered by the "Research on China's Engineering Science and Technology Development Strategy 2035." The results of the technology foresight project will provide a solid and reliable basis for identifying the key directions and initiatives in engineering science and technology for the next two decades, and for preparing field-specific technology roadmaps. Meanwhile, strategic research will be conducted in a more systematic and disciplined manner.

However, the technology foresight project implemented under the "Research on China's Engineering Science and Technology Development Strategy 2035" has some difficulties and issues to be addressed. In particular, completing an insightful and extensive technology foresight survey within a limited period of time; staying proactive to reflect the future requirements of industries; ensuring a fully represented and authoritative expert survey; and in-depth integration between technology foresight and strategic research. In view of this, the long-term strategic research on engineering science and technology will continue to move ahead with technology foresight conducted every five years as an integral part. In this way, what we have learned from this technology foresight project and other technology foresight activities, both domestically and abroad, will contribute to the continuous improvement of the foresight practices in engineering science and technology. First, on the basis of the problems identified and experiences gained, the existing methods and procedures will be refined to be more usable and adaptive; second, the use of quantitative analysis in various fields will be deepened over the five-year interval; lastly, a long-term mechanism for building a technology, knowledge, and expert library will be developed. In this process, technology foresight will play a stronger role through continuous improvement in terms of forward thinking and effectiveness.

\section{Acknowledgment}

This paper is based on the "Technology Foresight on China's Engineering Science and Technology to 2035," a project con- 
ducted by the research groups of the "Research on China's Engineering Science and Technology Development Strategy 2035" program. The program is jointly supported by the Chinese Academy of Engineering and the National Natural Science Foundation of China. The authors would like to acknowledge with gratitude the help and support of all academicians and experts participating in the expert surveys.

\section{References}

[1] National Institute of Science and Technology Policy. Japan's 10th science and technology foresight [R/OL]. (2015-08-12) [201610-15]. http://www.nistep.go.jp/aehiev/ftx/eng/mat077e/html/ mat077ae.html.
[2] Meng H, Xu Y, Li Z X.UK technology foresight for the 2020s and its enlightenment to China [J]. Forum on Science and Technology in China, 2013 (12): 155-160. Chinese.

[3] Foresight Horizon Scanning Centre, Government Office for Science. Technology and innovation futures: UK growth opportunities for the 2020s [R/OL]. (2012-11-23) [2016-10-16]. http://www.bis. gov.uk/foresight.

[4] Technology Foresight of China towards 2020 Research Group. Technology foresight of China towards 2020 [M]. Beijing: China Science Publishing \& Media Ltd (CSPM), 2006. Chinese.

[5] Shanghai Institute for Science of Science. The report of key areas of science and technology foresight of Shanghai (2013-2014) [M] Shanghai: Shanghai Scientific \& Technical Publishers, 2015. Chinese. 